\title{
Знание и мнение: их роль в науке и коммуникации
}

\author{
Е. Е. ЛЕДников
}

\begin{abstract}
The paper exposes notions of knowledge and belief specific traits of contexts, discerned in accordance with philosophical tradition. Perspectives of construction of rational theory of discussion about beliefs are evaluated.

Ключевые слова: знание, мнение, истина, коммуникация, рациональная полемика
\end{abstract}

Интерес к философскому осмыслению понятий знания и мнения возник в античную эпоху. Еще Парменид в V в. до н.э. противопоставил знание мнению, заявив, что о текучих, изменчивых предметах и событиях возможно только мнение, но не знание. Эта мысль Парменида в полной мере была воспринята и использована Платоном, превратившим в объект познания неизменные, вечные идеи и отказавшим в таком же статусе чувственно воспринимаемым, изменчивым вещам [2, с. 432-433]. Высказывания древнегреческих философов по поводу знания и мнения в наше время можно было бы истолковать как пожелание, чтобы наука исследовала и познавала устойчивые, повторяющиеся, воспроизводимые явления действительности, ибо именно через их изучение человеку раскрываются тайны бытия мира, а в отношении изменчивых, преходящих, уникальных событий ограничивалась бы мнениями.

Конечно, научное познание нельзя свести к простой регистрации единичных фактов, в качестве которых выступают не повторяющиеся, уникальные события. Но и без их фиксации наука невозможна - она лишится в этом случае значительной части своего эмпирического базиса. При этом фактические данные об имевших место землетрясениях, ураганах, эпидемиях, социальных катаклизмах и тому подобных событиях в истории человечества вовсе не являются «мнениями», хотя они и представляют 
собой регистрацию уникальных, не воспроизводимых событий. Одной из наиболее трудных задач науки как раз и является их изучение, формулировка закономерностей возникновения и протекания - крайне сложно, если вообще возможно, смоделировать то, что никогда больше не повторится (разумеется, при имевшем место наборе значений параметров, определявших ход перечисленных событий).

Следовательно, знание возможно как об «устойчивом», так и о «текучем». О первом, «устойчивом», оно получается, когда познающий человек конструирует абстрактные предметы с помощью абстракций отождествления, конструктивизации, идеализации, изолирующей абстракции, а затем устанавливает и формулирует законы взаимосвязи и взаимодействия этих предметов. О втором, «текучем», знание воплощается в сообщениях очевидцев, соучастников неповторимых, уникальных событий.

Различение знания и мнения, и это хорошо понимали уже мыслители древности, связано с их оценкой на истинность. Именно интенция (направленность) на истинность, осознание истинности некоторого высказывания превращает последнее в знание. В противном случае, если вопрос об истинности высказывания (или же системы высказываний) ставить преждевременно и даже вообще неуместно, его следует относить к мнению. Рассмотрим простейший случай, когда один человек полагает, что отдыхать следует на речке с удочкой, а другой - что лучше делать это во дворе за игрой в домино. Уместно ли в этом случае задаваться вопросом, чье мнение является «истинным»? Очевидно, что нет. Но и в более серьезных случаях вопрос об истинности может оказаться некорректным. Скажем, какой художественный метод (классицизм, реализм, абстракционизм) является истинным? Какая из мировых религий является истинной? В чем подлинный смысл жизни? Во всех этих случаях речь идет о мнениях, но никак не о знаниях, хотя в обратном нередко пытаются убедить окружающих сторонники тех или иных взглядов в соответствующих областях духовной культуры.

Относя важнейшие сферы духовной культуры к мнениям, мы никак не принижаем их роль в жизни человека. Нужно только помнить, что мнения представляют необходимое дополнение к знаниям, поскольку из одних только знаний духовный мир чело- 
века состоять не может. Мнения - это не только конвенции и гипотезы, но, прежде всего, положения, принимаемые в ходе развития цивилизаций, неотъемлемые их элементы. Разные мнения соответствуют разным цивилизациям. Скажем, у первобытных народов было принято ритуальное поедание предков, что совершенно нетерпимо в современном цивилизованном обществе. В рабовладельческом обществе существовало мнение (увы, закрепленное законами того общества), что рабы - не люди. Но при всей важности мнений поиски среди них «истинных» зачастую не только лишены смысла, но могут быть и социально опасными. Ведь духовная нетерпимость, которая принесла столько бед в истории человечества, одной из своих причин имеет необоснованную попытку истолковывать мнения как знания, отвергая одни мнения как ложные, а другие утверждая в качестве «единственно правильных» всеми доступными средствами насилия. С другой стороны, попытки возвысить знания над мнениями (как, скажем, это делал Св. Августин, противопоставлявший «знание, ведущее к спасению» праздному, суетному любопытству) в наше время ведут к сциентизму - необоснованному преувеличению возможностей науки, а, значит, в конечном счете, к ее компрометации. Вот почему важен как содержательно-философский, так и сугубо логический анализ этих понятий и контекстов, в которых они употребляются.

Говоря об истине, будем иметь в виду исключительно аристотелевское или же платоновское ее понимание. То есть теорию корреспонденции в первом случае и теорию когеренции во втором. Действительно, знание о мире - это утверждение о том, что есть «на самом деле», которое проверяется экспериментально или же гипотетико-дедуктивным методом. Знание о математических объектах - это утверждение, не противоречащее ранее доказанным положениям (скажем, из области теории чисел), причем это утверждение может быть представлено в качестве теоремы.

Разумеется, далеко не всегда знание - это явно установленная истина. Иногда утверждения относят к знанию по косвенным признакам - например, они удовлетворяют идеальным нормам знания (выражены в аксиоматической форме) или же их разделяет авторитетное научное сообщество по причине соответствия 
принятой парадигме. Однако в этом случае существует опасность принять за знание всего лишь мнение. Так, зачастую бывает трудно ответить на вопрос, является ли соответствующая парадигма образцом знания или феноменом мнения определенной научной группы (вспомним отношение официальной травматологии к новым методам лечения переломов, предложенным в 60-х годах курганским врачом-самородком Илизаровым). С другой стороны, сколько существует аксиоматически построенных рассуждений, попросту бесполезных в научном отношении! Так что косвенные свидетельства в пользу знания должны использоваться достаточно осторожно и критически.

Вопрос о специфике знания и мнения остро встает при разработке логических основ полемики о мнениях. Необходимость в полемике возникает всякий раз, когда люди, имеющие различные мнения по поводу тех или иных проблем, событий, предметов, пытаются устранить эти различия. А поскольку речь идет именно о мнениях, то цель подобной полемики - не столько в установлении истины, сколько в навязывании собственного мнения, а иногда и в отказе от него в пользу мнения оппонентов. В ходе такой полемики используется, как принято считать, прагматическая аргументация [4, с. 12]. Ее нередко противопоставляют логической аргументации, в ходе которой стремятся к обоснованию и расширению имеющихся знаний.

На первый взгляд, подобное противопоставление будто бы оправданно в свете того, что уже было сказано о различии знания и мнения. Заодно здесь уместно будет напомнить, что демократическое устройство общества предполагает уважение и терпимость к чужим мнениям, так что и о весьма серьезных расхождениях во мнениях спорить в цивилизованном обществе вроде бы не принято. И все же если предположить, что подобная полемика может возникнуть, то чтобы она привела к какомулибо плодотворному результату, она должна принять форму рациональной аргументативной дискуссии $[1$, с. 6-7]. А именно мнения должны быть выражены в виде утверждений, которые защищаются или критикуются. Стремление участников полемики убедить оппонента в приемлемости собственного и неприемлемости иного мнения должно осуществляться с помощью аргументативных утверждений, т.е. полемизирующие стороны 
не должны выходить за рамки интеллектуального состязания (не прибегать к угрозам, насилию, запугиванию и т.п.). Участники полемики должны обладать способностью к усвоению выдвигаемых аргументов, в том числе логического характера. Они должны быть готовы принимать логические следствия своих мнений, если самостоятельно или с помощью оппонентов обнаружат, что некоторые утверждения являются именно такими следствиями. Они должны быть готовы считаться с тем, что мнение оппонента может базироваться на некотором бесспорном положении, и отказаться от собственного мнения, если окажется, что оно вытекает из какого-либо сомнительного или вообще неприемлемого положения.

Более того, полемика имеет смысл только тогда, когда ее участники разделяют хотя бы одно мнение, пусть и не относящееся непосредственно к предмету полемики. Трудно согласиться с трактовкой K. Поппером «мифа концептуального каркаса», объявившего необязательным наличие у полемизирующих точек соприкосновения в виде «общего концептуального каркаса основных предпосылок» или же «соглашения о словаре» используемых терминов [3, с. 559-560, 590]. Участникам полемики можно предъявить и более сильное требование чтобы они были способны усмотреть логическую зависимость своих мнений от тех положений, которые являются точками соприкосновения. В противном случае полемика, может, и приведет к прояснению позиций ее участников (в чем Поппер видит самый значительный итог полемики), но достижения согласия во мнениях от подобной полемики ожидать не приходится. Как часто в современном мире мы наблюдаем длительные и бесплодные переговоры по тем или иным вопросам между странами!

Из всего сказанного напрашивается вывод, что если участники полемики не обременены логической культурой, то полемика вообще может не состояться. Так что логическая составляющая обязательно присутствует в любой аргументации, и вряд ли противопоставление логической аргументации прагматической должно выходить за рамки использования логически бесспорных либо прагматически убедительных аргументов - ведь структура аргументации будет одной и той же в обоих случаях, 
а оценивать виды привлекаемых аргументов без помощи логики невозможно.

Вместе с тем логика пока что может предложить лишь весьма идеализированные модели рациональной полемики, а это приводит к другой крайности. Коль скоро в них фигурируют идеальные субъекты знаний и мнений, обладающие неограниченными дедуктивными и аргументативными ресурсами, то каждый подобный субъект придерживается только мотивированных, в частности, логически обоснованных мнений, и нет в природе ничего такого, что могло бы побудить его отказаться от собственного мнения или хотя бы внести в него какие-либо изменения. Он «видит» как все следствия своих мнений, так и все предпосылки, из которых эти мнения следуют. Получается, что полемика между идеальными субъектами тоже вряд ли может состояться - ведь для нее отсутствуют какие-либо видимые причины. А вот в отношении реального субъекта мнения дело обстоит иначе. Каждый подобный субъект ограничен как в отношении дедуктивных ресурсов, которыми мог бы воспользоваться, так и в отношении запаса фактов, на которые мог бы опираться. Да и осознает он значимость, весомость далеко не всех аргументов. И поскольку невозможно предложить различие между идеальными и реальными субъектами знаний и мнений, пригодное для любого случая возникновения полемики, то сугубо логическая теория аргументации с ее базисной идеализацией оказывается недостаточной, а прагматическая теория, если в ней игнорировались бы логические основы полемики, была бы попросту неадекватной. Поэтому остается только согласиться с тем, что эффективного инструмента анализа «аргументативных дискуссий» пока не существует [1, с. 6-7], и объединить в создании такого инструмента усилия специалистов в области логики, теории аргументации, психологии и лингвистики.

\section{Литература}

[1] Емерен Франс Х.ван, Гроотендорст Р. Речевые акты в аргументативных дискуссиях. Санкт-Петербург: Нотабене, 1994.

[2] Платон. Тимей // Платон. Собр.соч: В 4 т. Т.3. М.: Мысль, 1994

[3] Попnер K. Логика и рост научного знания. М.: Наука, 1983.

[4] Сергеев B.M. Когнитивные методы в социальных исследованиях // Язык и моделирование социального взаимодействия. М.: Прогресс, 1987. 